\title{
La innovación educativa en la evolución de las profesiones. El caso de las Ciencias Laborales. Reflexiones y avances
}

\author{
Educational innovation in the evolution of professions. The case of Labor Sciences. \\ Reflections and advances \\ La innovació educativa en l'evolució de les professions. El cas de les Ciències \\ Laborals. Reflexions i avanços
}

Ricard Calvo-Palomares ${ }^{*}$, Juan Antonio Rodríguez-del-Pino ${ }^{\circledR}$

Departament de Sociologia i Antropologia Social, Universitat de València, Valencia, España

*Autor para correspondencia: Ricardo.Calvo@uv.es (Ricard Calvo-Palomares)

Recibido: 09/03/2020 | Aceptado: 20/05/2020 | Publicado: 24/12/2020

\section{Cómo citar:}

Calvo-Palomares, R. y Rodríguez-del-Pino, J. A. (2020). La innovación educativa en la evolución de las profesiones. El caso de las Ciencias Laborales. Reflexiones y avances. Research in Education and Learning Innovation Archives, 25,17-32. 10.7203/realia.25.16800

Copyright: El/La Autor/a. Open Access: Este es un artículo de acceso abierto distribuido bajo los términos de la licencia Creative Commons

Attribution-NoDerivatives 4.0 International licence (CC BY-ND 4.0)

Financiación: Proyectos de Innovación Educativa del Vicerectorat d'Ocupació i Programes Formatius de la Universitat de València desarrollados en el período 2013-2020
RESUMEN: Las profesiones están en continuo cambio y adaptación, y ello requiere de un permanente ajuste de las competencias que los/las profesionales precisan en cada momento. La Universidad actual debe asumir un papel activo que permita dicho ajuste. Es por tanto necesario que el estamento universitario tenga un amplio conocimiento de la realidad de la profesión, así como incorporar a sus dinámicas estas necesidades. En el presente texto proponemos una aproximación a la realidad de la profesión de Graduado Social -egresado/a actual en Ciencias Laborales ${ }^{1}$-como contexto de estudio, planteando el papel que la Universidad debería asumir en la actualidad como uno de sus elementos constitutivos. La importancia de los procesos de innovación docente como elementos necesarios para la mejora de la profesión. Muestra la experiencia de innovación docente desarrollada desde INVESLAB (Grupo de Investigación e Innovación en Ciencias Laborales de la Universitat de València), que ha propiciado la puesta en marcha de la Red Interuniversitaria de Innovación Docente en Ciencias Laborales. Red que ha superado el quehacer docente de una única universidad, que ha ido sumando profesorado de universidades de todo el territorio nacional (en la actualidad reúne un total de 53 profesores/as de 16 universidades distintas), y que busca, también, la colaboración con entidades de carácter profesional.

PALABRAS CLAVE: Ciencias Laborales; profesión; Graduado Social; innovación educativa; Observatorio

ABSTRACT: Because professions are constantly changing and adapting, a permanent adjustment of the skills needed by professionals at any given moment is required. Universities today must take on an active role that will enable such adjustments. University teaching staff must therefore have a broad knowledge of the reality of the profession and incorporate its needs into their own dynamics. In this study we propose an approximation to the Labor Relations profession today - currently a discipline in the field of Labor Sciences - as the context of study, highlight the role Universities must take on today as one of their constituent elements, and stress the importance of teaching-innovation

\footnotetext{
${ }^{1}$ A lo largo del texto haremos referencia a los estudios en Ciencias Laborales, como los estudios herencia acumulada por las titulaciones de Diplomatura en Graduado Social, Diplomatura en Relaciones Laborales, Licenciatura en Ciencias del Trabajo y la actual de Grado en Relaciones Laborales y Recursos Humanos.
} 
processes aimed at improving the profession. We present a teaching-innovation experience developed by INVESLAB (Research and Innovation in Labor Sciences research group of the University of Valencia) that has led to the creation of the Interuniversity Network for Teaching Innovation in Labor Sciences. This Network has gone beyond the teaching imparted at just one university by incorporating lecturers from throughout Spain (the network currently comprises 53 lecturers from 16 universities) and seeks collaboration with professional entities.

KEYWORDS: Labor Sciences; profession; Social graduated; educational innovation; Observatory

PARAULES CLAU: Ciències Laborals; professió; Graduat Social; innovació educativa; Observatori

RESUM: Les professions estan en continu canvi i adaptació, i això requereix un permanent ajust de les competències que els i les professionals necessiten a cada moment. La universitat actual ha d'assumir un paper actiu que permeta aquest ajust. És, per tant, necessari que l'estament universitari tinga un ampli coneixement de la realitat de la professió, i també que incorpore a les seues dinàmiques aquestes necessitats. En aquest text proposem una aproximació a la realitat de la professió de graduat social -graduat/ada actual en Ciències Laborals- com a context d'estudi, en què es planteja el paper que la universitat ha d'assumir en l'actualitat com un dels seus elements constitutius. La importància dels processos d'innovació docent com a elements necessaris per a la millora de la professió. Mostra l'experiència d'innovació docent desenvolupada des d'INVESLAB (Grup d'Investigació i Innovació en Ciències Laborals de la Universitat de València), que ha propiciat la posada en marxa de la Xarxa Interuniversitària d'Innovació Docent en Ciències Laborals, una xarxa que ha superat la tasca docent d'una única universitat, a la qual s'han anat sumant professorat d'universitats de tot el territori nacional (en l'actualitat reuneix un total de 53 professors/es de 16 universitats diferents) i que busca, també, la col-laboració amb entitats de caràcter professional.

Notas de aplicación práctica

Qué se sabe sobre el tema

- La universidad es un elemento (requisito para el ejercicio profesional.

- Las profesiones están en continuo cambio y requieren de una universidad que evolucione con ellas.

\section{Qué aporta este trabajo}

- Aporta el trabajo realizado a través de proyectos de innovación docente, como elemento de transferencia, intercambio y contacto entre el colectivo profesional y el mundo académico.

- Pone de manifiesto el papel de la innovación educativa en la evolución de las profesiones, en su proceso de configuración y mejora profesional.

Implicaciones para la práctica y/o política

- La necesidad de conocer de primera mano qué está ocurriendo en la realidad profesional (para lo que se propone la creación del Observatorio).

- Sirve de puente de unión entre la formación recibida por los-as egresados-as en Ciencias Laborales y las demandas que el mercado y la sociedad precisan.

\section{INTRODUCCIÓN: LAS PROFESIONES SE CONFIGURAN COMO REALIDADES SOCIALES}

Destacamos cuatro enfoques principales que determinan el estudio sistemático de las profesiones (Guillén, 1992; Sáez, 2003; Urteaga, 2008; Vallellano, 2019): el primero, dirige sus miradas hacia la identificación y definición de los rasgos característicos inherentes a la condición de profesional en una ocupación, estableciendo como su objetivo principal distinguir las profesiones de aquellas ocupaciones que no lo son; el segundo enfoque, aboga por graduar los niveles de profesionalización que asumen las ocupaciones; el tercer enfoque conforma una mirada hacia el funcionamiento de las distintas profesiones y su particular evolución social, centrando su interés en las 
relaciones de poder y privilegio que la condición profesional le otorga a una ocupación; y, un último enfoque, presenta una concepción de la profesión desde la complejidad de la acción profesional realizada, definiéndola como plural, integrada, intersubjetiva entre actores, situada y en la que existen distintas lógicas de actuación.

En este sentido, la profesionalización es un proceso que va cambiando con el tiempo, adaptándose a las distintas realidades con las que convive. Desde sus orígenes, la concreción y defensa de las actividades de sus integrantes se han convertido en su razón de ser. De ahí que la impermeabilidad de las profesiones sería tanto una aspiración como un recurso defensivo, permitiendo generar espacios propios y exclusivos (Remedi, 2015). En ello hay que tener en cuenta que determinados cambios ocurridos en las últimas décadas en el mercado de trabajo han deparado un proceso de acercamiento entre trabajadores asalariados y profesionales que dificultan esas ansias de distinción, por lo que en la sociedad actual del conocimiento proliferan las profesiones y profesionales, al tiempo que se debilita su estatus. Y son los nuevos perfiles profesionales, los más afectados por estos cambios, ya que responden a nuevas realidades en un contexto con nuevos condicionantes (Gómez y Tenti, 2011; Sánchez y Méndez, 2013).

Es por ello, que los fenómenos de profesionalización no siguen una secuencialidad predeterminada, las diferentes profesiones no siguen los mismos desarrollos, ni evolucionan a través de los mismos caminos, ni llegan a los mismos resultados, así, la profesionalización requiere, entre otras cosas, de interrogar a la práctica, (Sáez, 2003). Siendo un proceso dinámico que permite el avance integral del saber y del quehacer de la disciplina de forma consciente, comprometida y organizada, tanto individual como grupalmente, considerando los conocimientos, los principios y los valores humanos y sociales. Todas ellas, características propias del individuo que buscarán crear y generar acciones objetivas, racionales y sistemáticas, para beneficio propio y de las demás personas a quienes sirve. Pero el proceso de construcción de la identidad profesional es complejo y no siempre es exitoso. Tan solo puede hablarse de identidad cuando los actores sociales así lo interiorizan y empiezan a construir su sentido en torno a esa interiorización (Castells, 1997). Pero no en todos los casos asistiremos a la configuración profesional de una ocupación.

Como consecuencia, desde sus orígenes, el estudio del concepto profesión ha presentado dos dimensiones básicas de análisis, por una parte, la concreción intrínseca del conjunto de las propiedades objeto que definen su condición, y por otra, la determinación extrínseca de qué elementos se contienen o no en el conjunto de las realidades profesionales que esta asume (Haberstein, 1963). Siguiendo esta propuesta, nos preguntamos por los elementos constitutivos de una profesión, ya que según se manifiesten de una u otra manera, la configuración profesional puede ser muy distinta. Dependerá de: 1) el tiempo de experiencia acreditada; 2) la existencia de un cuerpo de conocimientos específicos; 3) un nivel competencial óptimo; 4) determinadas técnicas aplicadas en el desarrollo de la actividad; 5) un número (comunidad) representativo de miembros; 6) una formación superior (titulación oficial); 7) unos principios de actuación que configuren un código ético propio; 8) el reconocimiento de un colegio profesional; 9) reconocimiento de su utilidad social; 10) una autopercepción común de la profesión entre sus integrantes; y, 11) la autonomía y control sobre su proceso de trabajo. Estos elementos vendrán determinados según su naturaleza, bien considerados como internos, externos o contextuales a la actividad como tal (ver figura siguiente).

En este texto, se presenta un trabajo de discusión sobre la evolución de la profesión de las Ciencias Laborales y el papel que las acciones de innovación docente pueden tener como elemento facilitador en su proceso de configuración profesional. Para ello, estructuramos el discurso en primer término a partir de una valoración de la evolución profesional que estos estudios han tenido, analizando cada uno de los elementos que permiten configurar una actividad profesional. Lo que nos permite a continuación 
presentar el trabajo desarrollado por INVESLAB-UV desde 2013-2014 a través de procesos de innovación educativa vinculados con las competencias de la profesión. Y más concretamente el debate interno sobre balance del trabajo desarrollado hasta el momento, así como la estrategia a seguir en un futuro. Y en base a ello, cierra el texto, la propuesta que actualmente se está llevando a cabo de implantación de un Observatorio para el estudio de la evolución de las Ciencias Laborales en la Universidad española, como continuación de los proyectos y actividades ya realizadas.

\section{UN CASO DE ANÁLISIS: LA EVOLUCIÓN DE LA PROFESIÓN DE GRADUADO SOCIAL (ACTUALMENTE EGRESADO/A EN CIENCIAS LABORALES). UNA VALORACIÓN ANALÍTICA}

Conforme a lo expuesto ${ }^{2}$, la evolución de las profesiones es una realidad, que si bien se puede determinar estas evoluciones en diversos estudios relacionados con otras profesiones, la experiencia que presentamos se centra en el caso de las personas graduadas en Relaciones Laborales y Recursos Humanos, de la que carecemos de este tipo de estudios de referencia. Así, estos graduados y estas graduadas cumplen los elementos que definen y constituyen su esencia como profesional. Por lo que respecta al primero de ellos, el tiempo de experiencia acreditada, hay que ser consciente que cualquier actividad que se precie, requiere del cumplimiento de un requisito temporal que aporte las garantías experienciales suficientes como para acreditar su valía como tal. De ahí que sea preciso, apelar a la historia de la actividad como una de las variables fundamentales que describen su proceso de profesionalización. Si bien Graduado Social es una profesión consolidada con una trayectoria que se ha afianzado con el paso de los años, somos conscientes que su historia no responde a patrones como los estipulados para otras profesiones. Esto califica a la profesión como "joven". Realizar una aproximación a la realidad del Graduado Social supone tener presente que la evolución histórica de los estudios vinculados con las relaciones del trabajo ha ido muy ligada a la evolución propia que ha tenido el trabajo y con la concepción que del profesional de las Ciencias Laborales se ha tenido en cada momento:

En cuanto al segundo, la existencia de un cuerpo de conocimientos específicos. El poder de cualquier profesión (profesional) se fundamenta en la posesión de conocimiento formal, abstracto, esotérico y exclusivo (Friedman, 1986), que es necesario ${ }^{2}$ Este apartado toma como base empírica resultados de investigaciones realizadas por INVESLAB-UV
(2010, 2014 y 2016) o CEAL (Asociación Española de Auditores Sociolaborales).

Tabla 1. Clasificación o agrupación de los elementos que profesionalizan una ocupación según su naturaleza. Fuente: Calvo (2011a)

Factores internos o constitutivos de la actividad

Factores externos o de carácter social

\author{
Conocimientos específicos \\ Competencias \\ Técnicas \\ Utilidad social \\ Principios de actuación \\ Percepción común entre sus \\ miembros \\ Autonomía \\ Reconocimiento social \\ Reconocimiento universitario \\ (titulación superior) \\ Reconocimiento oficial (colegio \\ profesional) \\ Tiempo (experiencia) \\ Comunidad representativa
}




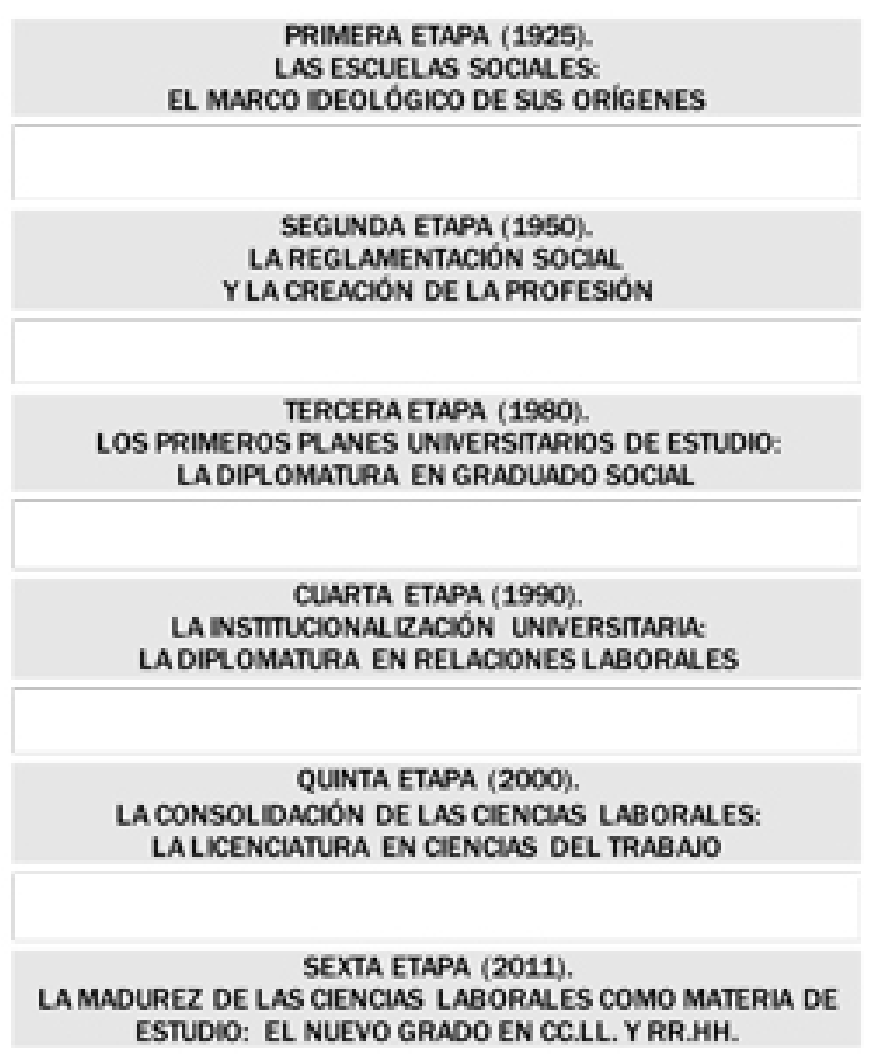

Figura 1. Evolución de los estudios en Ciencias Laborales. Fuente: Adaptación de Calvo (2011b)

crear, difundir y reproducir, protegiéndolo de las intrusiones de otros grupos profesionales (Guillén, 2003). Existe reconocimiento de una especificidad cuando un grupo profesional dispone de un savoir-faire que no es compartido con otros grupos. El factor trabajo se ha convertido en el epicentro sobre el que gira la actividad profesional que ha permitido generar ese savoir-faire propio que califica a este colectivo profesional, diferenciándolo del resto de profesionales con los que compite en el mercado laboral. Visión integral de las relaciones laborales y los recursos humanos que ha permitido poder trabajar las mismas desde y para las Ciencias Laborales.

A la esfera anterior cabe añadir dos más, la esfera del poder y la del querer. El profesional deberá contar con un nivel competencial óptimo para el desarrollo de su actividad, es decir con las habilidades y destrezas necesarias que le permitan poner en práctica los conocimientos teóricos adquiridos en sus años de preparación y demostrar así su capacidad para aplicarlos adecuadamente a cada situación concreta. Las competencias del colectivo se concretarán en la existencia de un cuerpo de valores y comportamientos actitudinales característicos de la actividad, que serán de gran ayuda para el cumplimiento de sus objetivos. Motivación, implicación o adaptación constante serán algunos de sus ejemplos más significativos. Por lo que competente no será tan solo aquel que pueda exhibir un título universitario, sino que será, además, quien tenga las habilidades y las capacidades para aplicar sus conocimientos a un problema -situación- específica y superarla con éxito. Este es un requisito configurador que la profesión de Graduado Social ha ido cumpliendo, a partir de la adaptación constante, la búsqueda de espacios profesionales que ocupar y la permanente mejora de su actividad, lo que se han convertido en sus señas identitarias de referencia.

Junto a ello, la necesidad de contar con determinadas técnicas aplicadas en el desarrollo de la actividad comunes a sus miembros. La existencia de un cuerpo de técnicas, instrumentos o herramientas que especializan el trabajo se convierte en un requisito 
esencial para su configuración profesional. Un cuerpo de metodologías con las que llevar a cabo sus actividades de acuerdo con los objetivos planteados por los destinatarios de las mismas. Los cambios que han afectado al factor trabajo en las últimas décadas no podrían ser entendidos sin las aportaciones realizadas desde este colectivo. Que ha permitido ir ajustando las metodologías, instrumentos y herramientas a las necesidades existentes.

El transcurso del tiempo debe materializarse irremediablemente en la existencia de un colectivo con una presencia considerable y significativaen la sociedad. Comunidad que compartirá además del quehacer profesional, todos aquellos rasgos propios definitorios que le permitirán diferenciarse del resto. Para que pueda existir una auténtica profesión, es condición necesaria que las personas que practican la ocupación formen un grupo relativamente homogéneo (Johnson, 1972). Así, lo colectivo tendrá un papel fundamental en el proceso. Este es uno de los requisitos que se cumplen en mayor medida, teniendo una evolución continuada al alza de la comunidad profesional.

Una misma formación (titulación académica acreditativa, reconocimiento universitario). Como señala (Guillén, 1990, 1992, 2003), el sistema educativo universitario y las organizaciones asociativas profesionales son las dos instituciones básicas que permiten la reproducción de las profesiones. Desde su incorporación en la década de los ochenta a la oferta de titulaciones oficiales de la universidad española y con el reconocimiento como Grado en la equiparación de títulos realizada en la década de los dos-mil, los estudios de Ciencias Laborales han conseguido afianzarse en la realidad universitaria actual.

Unos principios de actuación que configuren un código ético propio. De forma inseparable a la definición actual de profesión, se encuentra la existencia de un código de ética que dirija las actividades de cada profesión. Este código requiere de una conducta y práctica más allá de las obligaciones morales personales de cada individuo. Supone una dimensión ética del ejercicio de la profesión. Como reza, el lema en el anagrama oficial de los Graduados/as Sociales la "Justicia Social" que se convierte en su sello de identidad.

El reconocimiento de un colegio profesional. Aparecen los colegios profesionales como asociaciones de utilidad colectiva y pública que se caracterizan por defender y reglamentar una serie de principios normalizadores de la actividad profesional. Asumiendo los intereses colectivos del grupo como propios, velando por los intereses de la profesión, impulsando una legislación que la normará, promoviendo el desarrollo de sus miembros y determinando quien puede o no ejercerla. Pero las asociaciones o colegios profesionales no solamente controlan la cantidad de profesionales, sino también su calidad. Todo profesional acreditado tiene que ejercer de acuerdo con el código de ética de la profesión. Cualquier falta a este requisito supone el retiro de la licencia para ejercer. Los colegios profesionales garantizan la homogeneidad y uniformidad entre los miembros de una profesión y recalcan la heterogeneidad con otras profesiones u ocupaciones (Guillén, 1990). Requisito cumplido tanto a nivel provincial (COGRASOVA-Excmo. Colegio Oficial de Graduados Sociales de Valencia)como a nivel nacional (Consejo General de Colegios de Graduados Sociales de España) que ejercen una labor de autocontrol y regulación de la profesión, tanto de manera interna como externa.

Son también necesarios: por un lado, la existencia de un determinado reconocimiento público por parte de la sociedad, consistente en la valoración positiva de sus actuaciones, y por otro el requisito de la repercusión o la utilidad social de la actividad. La contribución de cualquier profesión -y por extensión del profesional que la desarrollaes una máxima para ella sin la que carecería de todo sentido. La búsqueda de la mejora del entorno en el que desarrolla su labor el profesional es un factor esencial para su reconocimiento explícito como tal. Podemos citar dos como los más destacados, el reconocimiento del estamento universitario a través de la determinación de unos 
estudios tendentes a la obtención de su acreditación, y el reconocimiento oficial a través de la autorización administrativa para la constitución de un colegio profesional.

También es precisa la autopercepción común de la profesión entre sus integrantes. La importancia de que aparezca un discurso profesional consistente, que se diferencie de lo ya existente, que encuentre su espacio social y su utilidad colectiva. Las profesiones están formadas por personas que han superado un período prolongado de educación universitaria, en el que han adquirido no solamente conocimientos técnicos, sino también una orientación vocacional (Guillén, 1990). Moore (1976) precisa que el conocimiento común es indispensable para mantener la unión de un grupo profesional. La identidad profesional se adquiere, cuando una persona se integra en un colectivo profesional, y adopta no solamente los conocimientos y habilidades de la profesión en cuestión, sino que, además, adopta los valores y las actitudes que la caracterizan Calvo et al. (2017). La construcción de la identidad profesional resulta de la articulación entre la identidad individual y la identidad colectiva (Boittin, 2002). El proceso de socialización profesional permite la adquisición de un sentimiento de pertenencia. Es en ese proceso, donde se integran los conocimientos, normas, valores, y cultura de la profesión.

Por último, la autonomía y control sobre su proceso de trabajo. La independencia en la toma de decisiones supone un elemento profesionalizador fundamental. El estudio de las mentalidades que caracterizan a cada grupo profesional en su conjunto, resulta esencial a la hora de analizar las luchas entre grupos profesionales por controlar esferas de actuación (Guillén, 1992, 2003). Un profesional, toma las decisiones más adecuadas a favor de un cliente conforme en base a la aplicación de unos principios generales, ofreciendo un servicio basado en las necesidades de Este.

\subsection{Una evolución no exenta de dificultades}

A partir de una metodología inductiva que se fundamentaba en lo recogido a través de los estudios realizados por INVESLAB-UV (2017) sobre la realidad de las Ciencias Laborales y los retos a los que se enfrentaría en un futuro no muy lejano, que pusieron de manifiesto cinco grandes puntos débiles que aportaba la profesión y que dificultaban que estos requisitos se completaran de manera plena. A partir de frases extraídas de entrevistas realizadas en el marco de los citados estudios ${ }^{3}$, estos cinco factores son:

1. Enfoque excesivamente orientado al ejercicio profesional, a lo aplicado y a la práctica. (“...nuestro trabajo lo es todo, el día a días no puede...”).

2. Ausencia de una trayectoria investigadora entre sus miembros. No se le ha dado importancia a esta dimensión (“... ¿investigar nosotros? ¿para qué? ¿qué vamos a decir? ¿a quién le puede interesar lo que nosotras sabemos? ...”"y...no llevamos bata blanca").

3. Subordinación a la Abogacía como hermana mayor, tutora durante mucho tiempo del devenir del futuro de la profesión (“...siempre hemos estado a la sombra de los abogados...”). Tanto es así que gran número de Graduados Sociales han cursado estudios de Derecho, permitiéndoles alcanzar una plenitud profesional que en determinados momentos no tenían como Diplomados).

\footnotetext{
${ }^{3}$ En 2014, se realizó un estudio previo a la propuesta de proyecto de innovación docente en el que se entrevistó a 24 especialistas egresados en Ciencias Laborales (19 Graduados Sociales, 2 Representantes de COGRASOVA-Colegio de Graduados Sociales de Valencia, 2 Diplomados en RRLL y un Graduado Social miembro de la Junta Directiva de CEAL). Las entrevistas fueron semiestructuradas y cuyo principal objetivo era conocer realidad de la profesión de Graduado Social, valorar las dificultades con las que se encontraba de cara a mejorar su futuro como realidad profesional.
} 
4. Escasa presencia de egresados/as en Ciencias Laborales en los claustros de profesorado universitario (“...yo no he tenido ningún profesor en la carrera, e hice las dos, que fuera Graduado Social...”).

5. La calificación como Asesores, aspecto que les ha restado importancia y relevancia social. (“... ¿quién puede ser asesora? Cualquiera .... y “...muchas veces que nos llamen asesores no nos beneficia...”).

6. La calificación como Asesores, aspecto que les ha restado importancia y relevancia social. (“... ¿quién puede ser asesora? Cualquiera .... y "...muchas veces que nos llamen asesores no nos beneficia...”).

\section{UN EJEMPLO DE INNOVACIÓN DOCENTE ADHOC A LAS NECESIDADES DE LA PROFESIÓN}

Los factores extraídos sirvieron de base para, desde Calvo et al. (2017), iniciar nuevos proyectos de innovación que actuaran, a modo de hipótesis, sobre dichas resistencias y paliaran sus efectos. Junto a estos factores, confluyeron otros que fueron capital importancia para el arranque del proyecto:

1. La no existencia de ningún proyecto similar vinculado con las Ciencias Laborales en territorio nacional, que aportara una dimensión "novedosa o innovadora" al mismo.

2. La limitada vinculación tradicional de los docentes con la titulación. La "empatía profesional" percibida habitualmente por el profesorado ha sido muy limitada, debido en gran medida a que ha sido una titulación de paso para buena parte de ese profesorado.

3. La aparición de profesorado "oriundo de las Ciencias Laborales o próximo a ellas" (titulados en Relaciones Laborales y Recursos Humanos, Graduado Social o Ciencias del Trabajo), interesados/as en la mejora de la titulación y que han potenciado esa visión desde y para las Ciencias Laborales.

4. La invitación cuasi inicial a participar a los estamentos profesionales (Colegio Oficial de Graduados Sociales de Valencia -COGRASOVA).

Tabla 2. Proyectos de innovación docente desarrollados. Fuente: Elaboración propia

\begin{tabular}{|c|c|c|}
\hline Curso & Código proyecto & Título del proyecto \\
\hline 2013-2014 & UV-SFPIE_DOCE 13-140974 & $\begin{array}{l}\text { Medios para la difusión de resultados de } \\
\text { investigaciones en Ciencias Laborales }\end{array}$ \\
\hline 2014-2015 & UV-SFPIE_DOCE14-217306 & $\begin{array}{l}\text { I Convocatoria de Premios de Trabajos de } \\
\text { Fin de Grado y Fin de Master en Ciencias } \\
\text { Laborales }\end{array}$ \\
\hline 2015-2016 & UV-SFPIE_GER15-314934 & $\begin{array}{l}\text { Consolidación de la Red Interuniversitaria } \\
\text { de Innovación Docente en Ciencias } \\
\text { Laborales }\end{array}$ \\
\hline 2016-2017 & UV-SFPIE_GER-16-414980 & $\begin{array}{l}\text { Dinamización de la Red Interuniversitaria } \\
\text { de Innovación en Ciencias Laborales }\end{array}$ \\
\hline $2017-2018$ & UV-SFPIE_GER17-584909 & $\begin{array}{l}\text { Desarrollo de la Red Interuniversitaria de } \\
\text { Innovación Docente en Ciencias Laborales }\end{array}$ \\
\hline 2018-2019 & UV-SFPIE_GER-18-849460 & $\begin{array}{l}\text { Red Interuniversitaria de Innovación } \\
\text { Docente en Ciencias Laborales. La } \\
\text { necesidad de mirar hacia el futuro }\end{array}$ \\
\hline
\end{tabular}


El proyecto iniciado en el curso académico 2014-2015, apostó por la constitución de la "Red Interuniversitaria de Innovación Docente en Ciencias Laborales", cuyo principal objetivo fue el de constituir una red de contacto entre profesorado con docencia en el Grado de RRLL y RRHH (profesorado procedente de distintas disciplinas: Sociología, Economía, Psicología, Empresa y Derecho, entre otras) que permitiera el intercambio de experiencias, el fomento de una visión propia -desde y para las Ciencias Laboralesque permitiera la mejora de la realidad docente y a la postre, de la realidad profesional. En la que participaron inicialmente, además de la Universitat de València, las Universidades de Huelva y Murcia, y que, en la actualidad, agrupa a 16 universidades españolas.

Tabla 3. Evolución del proyecto Fuente: Elaboración propia

\begin{tabular}{|c|c|c|c|}
\hline Curso & Universidades & Qué universidades & Núm. Prof. \\
\hline 2014-2015 & 3 & (València, Huelva y Murcia) & 13 \\
\hline 2015-2016 & 8 & $\begin{array}{l}\text { (València, Huelva, Murcia, UPV-EHU, } \\
\text { Cádiz, Salamanca, Illes Balears y } \\
\text { UPO-Sevilla) }\end{array}$ & 22 \\
\hline 2016-2017 & 11 & $\begin{array}{l}\text { (València, Huelva, Murcia, UPV-EHU, } \\
\text { Cádiz, Salamanca, Illes Balears, } \\
\text { UPO-Sevilla, León, Sevilla, y Pontificia de } \\
\text { Salamanca) }\end{array}$ & 48 \\
\hline 2017-2018 & 13 & $\begin{array}{l}\text { (València, Huelva, Murcia, UPV-EHU, } \\
\text { Cádiz, Salamanca, Illes Balears, } \\
\text { UPO-Sevilla, León, Sevilla, Pontificia de } \\
\text { Salamanca, Barcelona y Málaga) }\end{array}$ & 4 \\
\hline 2018-2019 & 16 & $\begin{array}{l}\text { (València, Huelva, Murcia, UPV-EHU, } \\
\text { Cádiz, Salamanca, Illes Balears, } \\
\text { UPO-Sevilla, León, Sevilla, Pontificia de } \\
\text { Salamanca, Barcelona, Málaga, } \\
\text { Zaragoza, Lleida y Granada) }\end{array}$ & 53 \\
\hline
\end{tabular}

La Red Interuniversitaria de Innovación Docente en Ciencias Laborales, planteó como principales líneas de trabajo las siguientes:

- Premios de Investigación en Ciencias Laborales. Desde el curso 2015-2016 gracias al convenio de colaboración firmado con ARELCIT (Asociación de Centros Universitarios de Relaciones Laborales y Ciencias del Trabajo), se pusieron en marcha estos premios para dar visibilidad a las investigaciones y estudios realizadas por las egresadas/os en Ciencias Laborales en sus Trabajos de Fin de Grado (TFG) o de Fin de Máster (TFM). Los miembros de la Red se convierten en el Jurado evaluador que revisa de manera anonimizada, ciega y secreta los trabajos presentados en cada convocatoria.

- Encuentros docentes de carácter específico y por materias, que permite que el profesorado que imparte una misma asignatura conozca a sus homólogos/as en otras universidades. Y con ello, la posibilidad de intercambio de materiales, metodologías y experiencias aplicadas.

Contacto con entidades vinculadas con las Ciencias Laborales y con sus salidas profesionales. Desde una perspectiva profesional, con Colegios de Graduados Sociales y Asociaciones de Auditores Sociolaborales o de Profesionales del Desarrollo Local y desde una perspectiva académica, con ARELCIT (Asociación de a) Centros Universitarios de Relaciones Laborales y Ciencias del Trabajo). 
Tabla 4. Convocatorias Premios de Investigación en Ciencias Laborales. Fuente: Elaboración propia.

\begin{tabular}{|c|c|c|c|c|}
\hline Curso & Edición & Ganadores & Temática & Procedencia \\
\hline 2015-2016 & I & $\begin{array}{l}1^{\circ} \text { Premio: Carlos Canet } \\
2^{\circ} \text { Premio: Amparo Bohigues } \\
1^{\circ} \text { Accésit: Daniel March } \\
2^{\circ} \text { Accésit: Magda Fernández }\end{array}$ & $\begin{array}{l}\text { Prec. laboral } \\
\text { Derecho trabajo } \\
\text { Derecho trabajo } \\
\text { PRL }\end{array}$ & $\begin{array}{l}\text { U. de València } \\
\text { U. de València } \\
\text { U. de València } \\
\text { U. de Murcia }\end{array}$ \\
\hline 2016-2017 & II & $\begin{array}{l}1^{\circ} \text { Premio: Cristina González } \\
2^{\circ} \text { premio: Patricia Montero } \\
1^{\circ} \text { Accésit: Mª́ngeles Jurado } \\
2^{\circ} \text { Accésit: José Javier Vila }\end{array}$ & $\begin{array}{l}\text { PRL Prec. laboral } \\
\text { Empleo } \\
\text { Form.Profesional }\end{array}$ & $\begin{array}{l}\text { U. de León } \\
\text { U. de València } \\
\text { U. de Málaga } \\
\text { U. de València }\end{array}$ \\
\hline $2017-2018$ & III & $\begin{array}{l}1^{\circ} \text { Premio: Raúl Payá } \\
2^{\circ} \text { premio: Lidia Chulià } \\
1^{\circ} \text { Accésit: MåMar Crespí } \\
2^{\circ} \text { Accésit: Marta Ferrer }\end{array}$ & $\begin{array}{l}\text { PRL Auditoría } \\
\text { laboral Derecho } \\
\text { trabajo Empleo }\end{array}$ & $\begin{array}{l}\text { U. de València } \\
\text { U. de València } \\
\text { U. Pompeu Fabra }\end{array}$ \\
\hline 2018-2019 & IV & $\begin{array}{l}1^{\circ} \text { Premio: Sergio Yagüe }{ }^{\circ} \\
\text { premio: Alberto García1 } \\
\text { Accésit: Soledad Gutiérrez2 } \\
\text { Accésit: Alexandra Lenis }\end{array}$ & $\begin{array}{l}\text { Derecho trabajo } \\
\text { Historia trabajo } \\
\text { PRL Economía } \\
\text { social }\end{array}$ & $\begin{array}{l}\text { U. de València } \\
\text { U. de León } \\
\text { U. de Córdoba } \\
\text { U. de Córdoba }\end{array}$ \\
\hline
\end{tabular}

Tabla 5. Convenios firmados. Fuente: Elaboración propia.

\begin{tabular}{|c|c|c|}
\hline Año & Entidad & Actividad principal desarrollada \\
\hline 2016 & $\begin{array}{l}\text { ARELCIT Asociación de Centros } \\
\text { Universitarios de Relaciones Laborales y } \\
\text { Ciencias del Trabajo }\end{array}$ & $\begin{array}{l}\text { I Premios de Investigación en Ciencias } \\
\text { Laborales }\end{array}$ \\
\hline 2016 & $\begin{array}{l}\text { COGRASOVA } \\
\text { Excmo. Colegio Oficial de Graduados } \\
\text { Sociales de Valencia }\end{array}$ & $\begin{array}{l}\text { Estudio "Graduados Sociales y Ciencias } \\
\text { Laborales. Un primer estudio del futuro de la } \\
\text { profesión" }\end{array}$ \\
\hline 2017 & $\begin{array}{l}\text { ARELCIT Asociación de Centros } \\
\text { Universitarios de Relaciones Laborales y } \\
\text { Ciencias del Trabajo }\end{array}$ & $\begin{array}{l}\text { Il Premios de Investigación en Ciencias } \\
\text { Laborales }\end{array}$ \\
\hline 2017 & $\begin{array}{l}\text { ARELCIT } \\
\text { Asociación de Centros Universitarios de } \\
\text { Relaciones Laborales y Ciencias del } \\
\text { Trabajo }\end{array}$ & $\begin{array}{l}\text { Estudio "Nuevas posibilidades de negocio para } \\
\text { los despachos laborales : ¿el momento de } \\
\text { incorporar un auditor sociolaboral?" }\end{array}$ \\
\hline 2017 & $\begin{array}{l}\text { COGRASOVA } \\
\text { Excmo. Colegio Oficial de Graduados } \\
\text { Sociales de Valencia }\end{array}$ & $\begin{array}{l}\text { Estudio "Nuevas posibilidades de negocio para } \\
\text { los despachos laborales : ¿el momento de } \\
\text { incorporar un auditor sociolaboral?" }\end{array}$ \\
\hline 2018 & $\begin{array}{l}\text { ARELCIT Asociación de Centros } \\
\text { Universitarios de Relaciones Laborales y } \\
\text { Ciencias del Trabajo }\end{array}$ & $\begin{array}{l}\text { III Premios de Investigación en Ciencias } \\
\text { Laborales }\end{array}$ \\
\hline 2018 & $\begin{array}{l}\text { COGRASOVA } \\
\text { Excmo. Colegio Oficial de Graduados } \\
\text { Sociales de Valencia }\end{array}$ & $\begin{array}{l}\text { Estudio "Nuevos escenarios para las Ciencias } \\
\text { Laborales (I)" }\end{array}$ \\
\hline 2019 & $\begin{array}{l}\text { Consejo General de Colegios de } \\
\text { Graduados Sociales de España }\end{array}$ & $\begin{array}{l}\text { IV Premios de Investigación en Ciencias } \\
\text { Laborales }\end{array}$ \\
\hline 2019 & $\begin{array}{l}\text { COGRASOVA } \\
\text { Excmo. Colegio Oficial de Graduados } \\
\text { Sociales de Valencia }\end{array}$ & $\begin{array}{l}\text { Estudio "Nuevos escenarios para las Ciencias } \\
\text { Laborales (II)" }\end{array}$ \\
\hline 2019 & $\begin{array}{l}\text { Consejo General de Colegios de } \\
\text { Graduados Sociales de España }\end{array}$ & $\begin{array}{l}\text { Observatorio Académico-Profesional para el } \\
\text { Estudio de la Evolución de los Estudios en } \\
\text { Ciencias Laborales }\end{array}$ \\
\hline
\end{tabular}


- Jornadas de Experiencias de Innovación Educativa en Ciencias Laborales. Dedicada cada año a una temática sociolaboral de interés (ver tabla siguiente) y que a su vez se convertían en el momento de entrega de la convocatoria anual de los Premios de Investigación.

Tabla 6. Jornadas de innovación desarrolladas. Fuente: Elaboración propia.

\begin{tabular}{|c|c|c|}
\hline Fecha & Edición & Temática \\
\hline 08-07-2016 & I JEICL & Las Ciencias Laborales como espacio para la innovación \\
\hline 07-07-2017 & II JEICL & $\begin{array}{l}\text { Las Ciencias Laborales y la Formación y Orientación Laboral: dos } \\
\text { espacios para la innovación }\end{array}$ \\
\hline 06-07-2018 & III JEICL & Emprendimiento: discursos, retos y experiencias en el aula \\
\hline 28-06-2019 & IV JEICL & $\begin{array}{l}\text { Rompiendo estereotipos de género en el mundo educativo y } \\
\text { laboral }\end{array}$ \\
\hline
\end{tabular}

- Publicación de los trabajos premiados en la convocatoria de Premios de Investigación, así como las experiencias docentes presentadas en cada una de las ediciones de las Jornadas.

Tabla 7. Publicaciones realizadas. Fuente: Elaboración propia.

\begin{tabular}{ll}
\hline Año & Título \\
\hline 2017 & $\begin{array}{l}\text { Investigación e innovación en Ciencias Laborales El caso de INVESLAB y de la Red } \\
\text { Interuniversitaria de Innovación Docente en Ciencias Laborales }\end{array}$ \\
2017 & $\begin{array}{l}\text { Las Ciencias Laborales y la Formación y Orientación Laboral: dos espacios para la } \\
\text { innovación }\end{array}$ \\
2018 & Ciencias Laborales y emprendimiento: discursos, retos y experiencias de aula \\
2019 & Rompiendo estereotipos de género en el mundo educativo y laboral \\
\hline
\end{tabular}

\section{UN PROYECTO QUE SE RE-INNOVA: UNA REFLEXIÓN PARA EL FUTURO}

A partir de la experiencia de innovación docente implantada, y después de cinco años de vigencia del proyecto, creímos oportuna la reflexión interna. Para ello, y pensando en la operatividad de la dinámica de trabajo (no podemos obviar la dificultad que genera que el proyecto aglutine a 53 profesores/as de 16 universidades distintas y distantes geográficamente), se decidió constituir dos grupos de trabajo, uno que integrado por los miembros del proyecto de la Universitat de València (de los que finalmente participan cinco) y otro con el resto de miembros de la Red (de los que finalmente participan ocho, procedentes de seis universidades distintas, y uno en representación de COGRASOVA).

Dos fueron los temas que centraron el debate de ambos grupos, por una parte, hacer balance del trabajo realizado hasta el momento, y por otro establecer las posibles líneas estratégicas a seguir en los próximos años. Por lo que respecta a la primera, seis fueron los aspectos clave (ventajas o beneficios observados o generados por el proyecto) más valorados por los participantes:

- Visión multidisciplinar, gracias a la participación en el proyecto de profesorado procedente de departamentos y áreas muy variadas, tales como la Sociología, Economía, Psicología o el Derecho, entre otras. Se veía reflejado en los siguientes comentarios: 
Tabla 8. Participantes en los grupos. Fuente: Elaboración propia.

\begin{tabular}{|c|c|c|c|c|}
\hline Código & Número & Procedencia & Reunión inicial & Reunión final \\
\hline $\begin{array}{l}\text { G1 Grupo } 1 \\
\text { (miembros } \\
\text { INVESLAB-UV) }\end{array}$ & 5 & Universitat de València & $\begin{array}{l}\text { Valencia } \\
07 / 05 / 2019\end{array}$ & Valencia30/06/2019 \\
\hline $\begin{array}{l}\text { G2 Grupo } 2 \\
\text { (miembros } \\
\text { RED) }\end{array}$ & 8 & $\begin{array}{l}\text { Universidad de Málaga } \\
\text { Universidad de Granada (y } \\
\text { representante de ARELCIT) } \\
\text { Universidad de Huelva } \\
\text { Universidad de Sevilla } \\
\text { Universidad de Valencia } \\
\text { Universidad de Murcia } \\
\text { COGRASOVA }\end{array}$ & $\begin{array}{l}\text { Málaga } \\
\text { 10/05/2019 }\end{array}$ & $\begin{array}{l}\text { Melilla } \\
18 / 07 / 2019\end{array}$ \\
\hline
\end{tabular}

...la multidisciplinariedad de los estudios la tenemos en el ADN del proyecto, venimos de disciplinas muy variadas, tú Sociología, yo Economía, Derecho, etc...

...la multi e interdisciplinariedad es una valor añadido...

- Nacido desde y para las Ciencias Laborales. Surge con la finalidad de aportar algo para esta titulación y lo hace desde el conocimiento de su realidad. Así nos lo hacía saber uno de los profesores participantes:

...que algunos de nosotros seamos egresados en Relaciones Laborales es muy positivo, conocemos perfectamente la titulación porque la hemos sufrido en primera persona...

- Contacto directo y permanente con las entidades representativas, tanto profesionales como académicas. En esta dirección van las citas siguientes:

...ahora que empezamos a entendernos...hay que aprovecharlo

...muy importante, ir de la mano del Colegio...

...que el Consejo General de Colegios de Graduados Sociales se sume al proyecto es muy importante...representa a todos los Colegios Oficiales de España...

- Nace para cubrir necesidades existentes, no existencia de ninguna estructura similar, carencia de la visión investigadora entre el colectivo de Graduados Sociales.

- Proyecto que busca sumar esfuerzos desde su concepción. Búsqueda de la complementariedad de manera continua.

...la suma de esfuerzos es indudablemente uno de nuestras grandes fortalezas...

- Dar sentido profesional a una nueva realidad docente.

...hay que buscar puntos de encuentro...la Universidad debe nutrirse de lo profesional para mejorar, no hay otra opción...

Por lo que respecta a la discusión generada en torno a la estrategia a tomar, se establecieron como principios de actuación tres: en primer término, mantener y afianzar 
el trabajo realizado hasta el momento (línea inédita no existente), ya que las Ciencias Laborales son un espacio que necesita de proyectos como estos que impulsen su presencia; en segundo, la idoneidad de consolidar la visión conjunta, de confluencia de lo académico con lo profesional y/o viceversa; y por último, el futuro de la profesión -mejora profesional- pasa por la mejora en aspectos vinculados con la innovación en las aulas. Valgan como ejemplificaciones de todo ello, los siguientes comentarios realizados por los participantes en los grupos:

...hay que mantener el trabajo iniciado de intercambio con el mundo profesional, es el camino para la mejora...

...hemos iniciado un camino difícil, no exento de dificultades - todo lo nuevo genera resistencias- pero es necesario, y que hay que mantener a toda costa...

...yo creo que RRLL-RRHH son unos estudios que han cumplido la mayoría de edad y por tanto tienen que empezar a plantearse qué quieren ser de mayores...

...las universidades tenemos que asumir nuestro papel motor y no esperar a que el mercado nos lo pida, debemos adelantarnos e innovar...

...mejorar la profesión pasa por mejorar los estudios y mejorar los estudios pasa por mejorar la profesión, son dos compañeros inseparables de viaje...

...RRLL goza de buena salud como estudios, y la profesión está en un momento de adaptación, es por tanto un momento importante...

...nos hacen falta informaciones concretas de nuestros estudios, no los tenemos, ni nos hemos preocupado de tenerlos, ni desde las Universidades ni desde los Colegios profesionales...

...la universidad debe estar atenta a lo que ocurre a su alrededor...no puede esperar a que lo profesional venga a buscarla, eso no va a pasar, debe moverse y salir a buscar la realidad para actuar sobre ella...

\section{A MODO DE CONCLUSIÓN FINAL: LA CREACIÓN DEL OBSERVATORIO}

En conclusión, podemos afirmar que, si bien existen otros proyectos de innovación en el entorno universitario español que vinculan la universidad con el mundo laboral (algunos desarrollados en la Universidad de Deusto, Universidad de Navarra o Universidad de Valladolid, por ejemplo), no creemos que nos sirvan de referencia directa, ya que no se plantean como objetivos la mejora de una profesión en concreto, ni mucho menos el análisis y conocimiento de su realidad en el mercado de trabajo. Tampoco lo hacen vinculado específicamente nuestra área de conocimiento, las Ciencias Laborales, por lo que nuestra propuesta goza de una vida propia en este sentido. El proyecto que presentamos resulta novedoso en el panorama español por dos principales razones: en primer término, porque ha mantenido una continuidad a lo largo de siete años, introduciendo innovaciones y nuevos actores curso a curso, lo que pone de manifiesto su potencialidad en el tiempo; y en segundo, porque si bien existen experiencias de Observatorios -valgan como referencia y más destacados vinculados con lo sociolaboral, los de empleabilidad y empleo universitarios en el cual participa la Conferencia de Rectores Universitarios (CRUE), la Cátedra Unesco y la Caixa y el Observatorio de la 
Profesión del Consejo General de Colegios de Graduados Sociales- no se plantean una actuación tan concreta ni tan aplicada como la que realizamos desde nuestro proyecto, consiguiendo con ello una potencialidad en cuanto a su repercusión de alto interés para la comunidad científica. El que aquí describimos introduce una visión a largo plazo, en el sector específico de la Ciencias laborales puesto que, como apuntaba una de las participantes en uno de los grupos de trabajo, "...un observatorio es un proyecto clave de futuro, lo necesitamos como profesión y como Universidad..., la creación del Observatorio se convierte en una apuesta estratégica de futuro. La presente Red Interuniversitaria tiene la ambición de lograr una intervención integral en todos los ámbitos académicos y laborales entre las personas egresadas en Relaciones Laborales y Recursos Humanos. Este que resulta un objetivo, aparentemente muy obvio, no lo es tanto cuando analizamos de cerca otros estudios universitarios y su vinculación con la profesión que se deriva de los mismos. Es por esta razón, por la que resulta necesaria la continuidad del contacto entre lo académico con lo profesional a través de la creación de un Observatorio de la evolución de la titulación, entendido como un espacio que permita generar informaciones específicas de la realidad de los estudios desde la perspectiva de su integración en el mercado de trabajo, y que permita tomar las decisiones más adecuadas al respecto.

Los observatorios están destinados a captar, organizar, evaluar y procesar información para poder difundir conocimientos (Prieto, 2003). Su objetivo estratégico es proponer actuaciones para el mejoramiento de la calidad educativa con efectos en la realidad profesional y/o viceversa. En acuerdo con la identidad de las entidades integrantes del mismo (Universitat de València, Consejo General de Colegios de Graduados Sociales de España, COGRASOVA-Excmo. Colegio de Graduados Sociales de Valencia, ARELCIT-Asociación de Centros Universitarios de Relaciones Laborales y Ciencias del Trabajo y AERELABO- Asociación Interuniversitaria de Estudiantes de Relaciones Laborales, Recursos Humanos/Graduado Social), este Observatorio supone una unidad que integra y articula los procesos de diagnóstico y evaluación académica y profesional. Su diseño se fundamenta en el trípode necesario para la mejora: diagnóstico, intervención, plan de desarrollo. Todo observatorio busca dos propósitos elementales: investigar - revisar, describir, caracterizar, evaluar, discutir, cuestionar, sugerir- los contenidos que aparecen en el espacio de observación pertinente a su área de interés; e informar a la comunidad los hallazgos que ocurren en ese proceso, fundamentadas en argumentos científicos.

En el curso 2019-2020 se ha concretado en una nueva línea de trabajo de INVESLABUV y de la Red Interuniversitaria. Concretamente para esta primera edición del Observatorio, se propuso una actuación encaminada a constatar la presencia de titulados/as en Ciencias Laborales en la Universidad española, aspecto que nos dará una muy buena imagen del grado de aceptación que nuestros estudios tienen en este ámbito: Para ello se propone entrar en contacto con todos aquellos centros universitarios que imparten los Grados de RRLL y RRHH y preguntar al profesorado que imparte docencia en la misma tres preguntas muy básicas: ¿hemos sido realmente aceptados? ¿de qué manera? ¿qué barreras quedan por superar?

Tres son las conclusiones que se pueden extraer:

1. Que las profesiones evolucionan en el tiempo, que deben adaptarse a los cambios en función del contexto en el que se encuentran. Los elementos que conforman su realidad se encuentran en movimiento. En este sentido, la Universidad debe dejar de ser tan solo una entidad certificadora de egresados para pasar a un papel más activo -de intercambio- con lo profesional. Así, este modelo es una muestra que puede y debe ser transferido para mostrar las interconexiones y anclajes que existen entre otros estudios universitarios y el ámbito laboral en el que se desarrollan profesionalmente. 
2. El proyecto presentado, desde la esfera de la innovación docente, responde a la necesidad de que la Universidad esté atenta a lo que ocurre a su alrededor, a la realidad de la profesión. Para ello, es necesario que ambas partes se reconozcan, busquen y complementen. Deben buscar puntos de encuentro e intercambio permanentes, continuos y estables en el tiempo. En este sentido, la Universidad debe reconocer al colectivo profesional (Colegio o Asociación) como el actor habilitado con un conocimiento aplicado, visión que debe incorporarse a la academia de manera necesaria. Y por su parte, el colectivo profesional debe ver en la Universidad, el referente teórico que permite la reflexión y la formación de ideas como elemento clave de la configuración de los nuevos profesionales. Por tanto, la búsqueda de una interacción entre ambos se convierte en una premisa básica para la mejora continua.Una precaución que se debe de tener con el Observatorio, es la necesidad de interactuación continua entre todos los actores participantes. Todos ellos deben ver este instrumento como una necesidad para sus intereses. Para ello se precisa la retroalimentación constante del mismo. Si no, se puede caer en la obsolescencia de manera muy rápida.

3. Resulta preciso conocer de primera mano qué está ocurriendo en la realidad profesional, por lo que la existencia de un Observatorio académico-profesional de la evolución de los Estudios de Ciencias Laborales, se convierte en una necesidad operativa para alcanzar la mejora de la profesión.

\section{AGRADECIMIENTOS}

Nuestro agradecimiento a José Reyes Ruíz, compañero, amigo y profesor de la Universidad de Castilla La Mancha (UCLM) por la revisión previa realizada, por sus sugerencias y aportaciones.

\section{REFERENCIAS}

Boittin, I. (2002). Etudiants en soins infirmiers de deuxième année: crise identitaire. Recherche en soins infirmiers, 68, 66-92. Descargado de https://bdsp-ehesp.inist.fr/ vibad/index.php?action=getRecordDetail\&idt $=244744$

Calvo, R. (2011a). AEDL (Agente de Empleo y Desarrollo Local): Una aproximación sociológica al estudio de una nueva profesión (Tesis Doctoral, Universitat de València, Valencia). Descargado de https://www.tdx.cat/handle/10803/81337

Calvo, R. (2011b). El desarrollo local como salida profesional para los titulados en ciencias laborales. Trabajo. Revista andaluza de relaciones laborales(25-26), 235-251. Descargado de http://hdl.handle.net/10272/6934

Calvo, R., Rodríguez, J. A., Lorente, R., Benedito, M. A., Cantarero, S., y Cano, F. J. (2017). INVESLAB. Innnovación e investigación en Ciencias Laborales desde y para las Ciencias Laborales. En F. Cano y R. Calvo (Eds.), Investigación e innovación en Ciencias Laborales. El caso de INVESLAB y de la Red Interuniversitaria de Innovación Docente en Ciencias Laborales (pp. 115-133). Valencia: Neopatria.

Castells, M. (1997). La era de la información. Madrid: Alianza Editorial.

Friedman, M. (1986). Libertad de elegir: hacia un nuevo liberalismo económico. México: Grijalbo.

Gómez, V. M., y Tenti, E. (2011). Universidad y profesiones. Crisis y alternativas. Buenos Aires: Miño y Dávila Editores.

Guillén, M. (1990). Profesionales y burocracia: Desprofesionalización, proletarización y poder profesional en las organizaciones complejas. Reis: Revista española de investigaciones sociológicas(51), 35-52. https://doi.org/10.2307/40183479 
Guillén, M. (1992). El sistema de profesiones: el caso de las profesiones económicas en España. Reis: Revista española de investigaciones sociológicas, 59(92), 243-259. Descargado de http://reis.cis.es/REIS/PDF/REIS_059_11.pdf

Guillén, M. (2003). El sistema de profesiones: el caso de las profesiones económicas en España. En M. Sánchez, J. Sáez, y L. Svensson (Eds.), Sociología de las profesiones. Pasado, presente y futuro. Murcia: Diego Martín Librero Editor.

Haberstein, R. W. (1963). Funeral customs the world over. Milwaukee: Buffin Printers. Johnson, T. J. (1972). Professions and power. Londres: McMillan Press.

Moore, W. E. (1976). The professions: roles and rules. New York: Russell Sage Foundation.

Prieto, R. (2003). Observatorios en Internet. Servicio de observación sobre internet. Boletín semanal, 240.

Remedi, E. (2015). Instituir quehaceres. La universidad y las profesiones: proceso que se entrecruzan. Universidades(63), 5-8. Descargado de https://www.redalyc.org/pdf/373/ 37339255002.pdf

Sáez, J. (2003). Las profesiones sociales: la educación social en perspectiva. En M. Sánchez, J. Sáez, y L. Svensson (Eds.), Sociología de las profesiones: pasado, presente y futuro. Murcia: Diego Martín Librero Editor.

Sánchez, H., y Méndez, S. (2013). ¿Perfiles profesionales 2.0? Una aproximación a la correlación entre la demanda laboral y la formación universitaria. Estudios sobre el Mensaje Periodístico, 19, 981-993. https://doi.org/10.5209/rev_ESMP.2013.v19.42183

Urteaga, E. (2008). Sociología de las profesiones: una teoría de la complejidad. Lan Harremanak. Revista de Relaciones Laborales, 18, 169-198. Descargado de https:// ojs.ehu.eus/index.php/Lan_Harremanak/article/viewFile/2812/2428

Vallellano, M. D. (2019). La satisfacción laboral en profesiones asistenciales. De la investigación comparativa en trabajo social a una propuesta de intervención (Tesis Doctoral, Universidad Complutense de Madrid, Madrid). Descargado de https:// eprints.ucm.es/59695/1/T41873.pdf 